\title{
ArcheoSciences
}

Revue d'archéométrie

33 (suppl.) | 2009

Mémoire du sol, espace des hommes

\section{D Electrical Resistivity Tomography survey optimisation of solute transport in porous media}

Gregory Lekmine, Marc Pessel and Harold Auradou

\section{(2) OpenEdition}

1 Journals

\section{Electronic version}

URL: https://journals.openedition.org/archeosciences/1756

DOI: 10.4000/archeosciences. 1756

ISBN: 978-2-7535-1599-4

ISSN: 2104-3728

Publisher

Presses universitaires de Rennes

\section{Printed version}

Date of publication: 30 October 2009

Number of pages: 309-312

ISBN: 978-2-7535-0943-6

ISSN: $1960-1360$

\section{Electronic reference}

Gregory Lekmine, Marc Pessel and Harold Auradou, "2D Electrical Resistivity Tomography survey optimisation of solute transport in porous media", ArcheoSciences [Online], 33 (suppl.) | 2009, Online since 30 October 2011, connection on 21 September 2021. URL: http://journals.openedition.org/ archeosciences/1756 ; DOI: https://doi.org/10.4000/archeosciences. 1756 


\title{
2D Electrical Resistivity Tomography survey optimisation of solute transport in porous media
}

\author{
Gregory Lekmine*, Marc Pessel* and Harold Auradou **
}

Key words: Resistivity, Tomography, Porous media, ERT, 2D models.

The purpose of this study is to quantify experimentally the evolution of dissolved species in porous media from 2D resistivity models. Transport experiments are done at the lab level by performing flow in a model porous medium obtained by filling a transparent container with mono disperse glass beads. A tracer made by mixing a dissolved blue dye and a known $\mathrm{NaCl}$ concentration is injected with a constant flow rate through the porous medium already saturated by a transparent fluid. ERT measurements are acquired during the fluids flow. The measurement conditions and the inversion parameters are estimated so that the relation between spatial and temporal resolutions is optimised. A video follow-up is also carried out during the flow. A comparison of the temporal evolution of the $\mathrm{NaCl}$ concentration distribution estimated from ERT models with video analysis shows remarkable agreement.

Electrical resistivity tomography is used to detect the contaminant's plumes in saturated porous media using the resistivity contrasts between the fluids saturating initially the pore spaces and the moving fluids (Binley, 1996; Oldenborger et al., 2007). Archie's law (1942) relates the measured bulk apparent conductivities to the fluids resistivity in the poral network via a priori information about the porosity and the particles cementation state. As previously shown by (Slater et al., 2000), it is possible to use this method to estimate the tracer spatial reparation in terms of concentrations. This method is non-invasive and non-destructive, but it is based on indirect measurements of the electrical properties. The electrical conductivity distribution is obtained through data inversion. However the non-unicity of solution can lead to misinterpretations of the geological reality. We test the model's reliability in laboratory conditions by experiments in porous media at mesoscopic level where the hydrodynamic parameters can be easily estimated. We optimise the protocols of measurements and inversions according to the medium's geometry for tracer follow-up. The built models are then expressed in terms of tracer concentration distribution on several time steps and compared to the estimated concentrations by a parallel video follow-up.

\section{EXPERIMENT PROTOCOL}

The flow experiments are carried out in a transparent Plexiglas container (with a volume of $\mathrm{V}=\mathrm{HxLxE}=233.75 \mathrm{~cm}^{3}$ ) filled with glass beads of 166 microns diameter. Porosity is $\Phi$ $=0.365$, close to the theoretical value estimated by (Gondret, 1994): the porous medium may be considered homogeneous and isotropic. Hydrodynamic parameters are supposed constant, and the edge effects on the porosity are neglected since the pores diameter is small in comparison to the wall dimensions (Gondret, 1994). A permeable nylon fabric of $100 \mu \mathrm{m}$ mesh covers the lower opening of the container. This part is in contact with a tank which contains the tracer,

* Laboratoire IDES-UMR 8148, Université Paris Sud bâtiment 504 - 91405 Orsay Cedex.

** Laboratoire FAST-UMR 7608, Universités Paris Sud \& Paris VI bâtiment 502 - 91405 Orsay Cedex. 
whereas three injectors in the sealed upper cover ensure a constant flow rate (Fig. 1a). Two lines of twenty one electrodes of $1.5 \mathrm{~mm}$ diameter, spaced every $1 \mathrm{~cm}$ are installed along the edges of the cell (Fig. 1b). The first and the last electrode of each line are located respectively at $3.5 \mathrm{~cm}$ of the lower and upper opening of the container. This kind of electrodes configuration reproduces the measurements conditions used in a borehole.

Four experimental conditions must be respected in order to optimise the ERT follow-up of tracer propagation (Slater et al., 2000):

$1 /$ all the pore space is saturated;

$2 /$ the matrix conductivity is low in comparison to tracer conductivity;

$3 /$ temporal variations of electric conductivity are only due to conductivity changes of interstitial fluids;

4/ electrical conductivity is linearly related to tracer concentration.

Prior to any experiments, the tank in contact with the lower opening is filled by a transparent fluid, which is pumped upwards by the injectors until total saturation of the medium. This fluid is produced by dissolution of a small

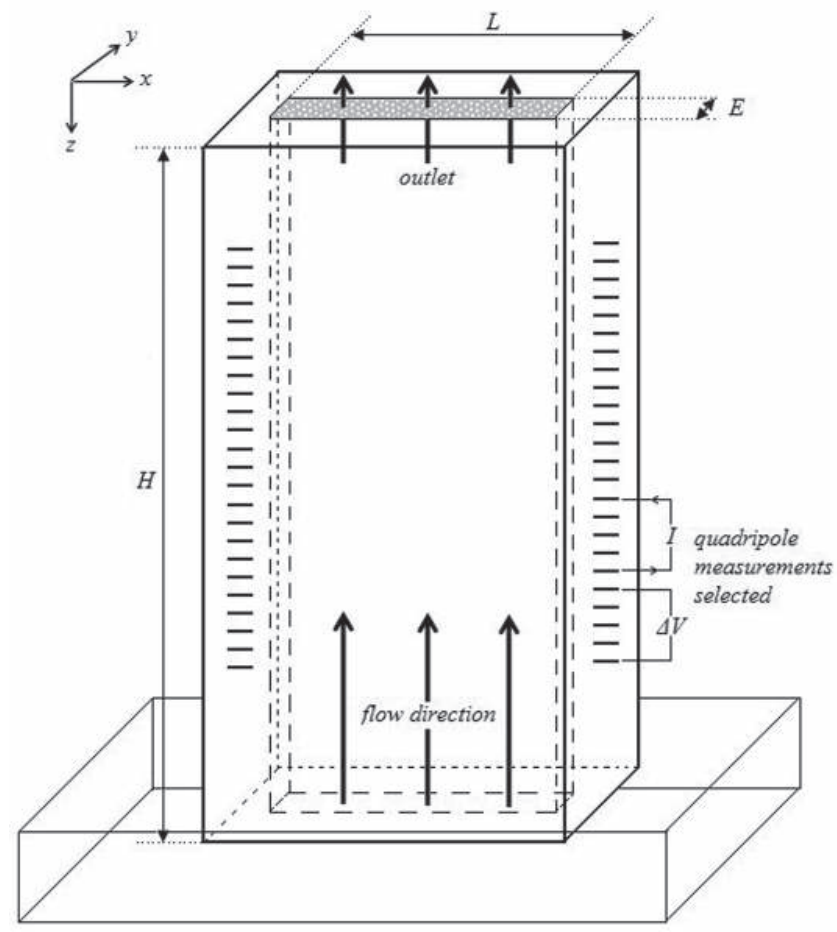

Figure 1a: Schematic of the experimental Plexiglas cell filled with spherical glass beads of 125 to 166 micron diameter. $H=27.5 \mathrm{~cm}$, $L=8.5 \mathrm{~cm}, E=1 \mathrm{~cm}$.

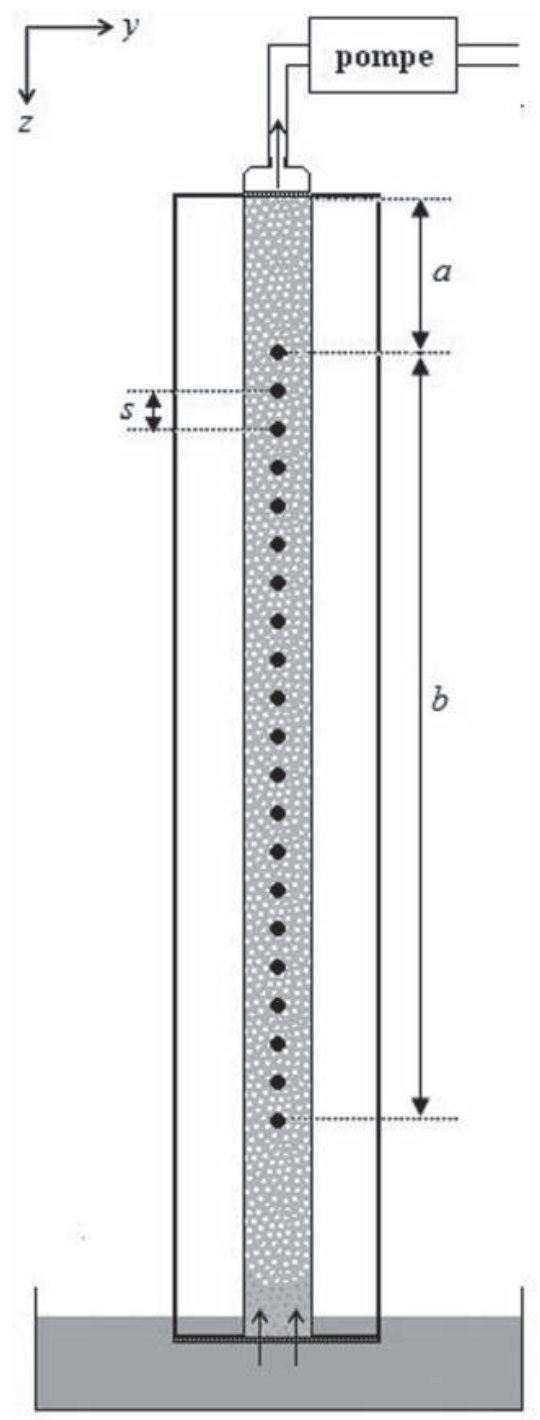

Figure 1b: Side view of the experimental device. $s=1 \mathrm{~cm}$, $a=3.5 \mathrm{~cm}, \mathrm{~b}=21 \mathrm{~cm}$.

amount of $\mathrm{NaCl}$ in degassed and demineralised water. The pumping rate $(1.5 \mathrm{ml} / \mathrm{min})$ is sufficiently low to obtain a perfect saturation of the medium. The tracer is obtained by dissolution of $0.1 \mathrm{~g} / \mathrm{L}$ blue dye mixed with $1.0 \mathrm{~g} / \mathrm{L} \mathrm{NaCl}$ in demineralised water.

The two fluids are miscible, have the same viscosity and their different $\mathrm{NaCl}$ concentration creates a small density difference. During the experiments a mixing zone appeared between the two fluids: its characteristics depend upon the densities contrasts, pore size and flow rate.

The geometry evolution of this zone is observed, at the same time, by two independent techniques: the video follow-up which links transmitted light intensity through the cell measured on each pixel of the camera to the dye concentration, and the electrical measurements which reveal 
the $\mathrm{NaCl}$ dispersion during transport. The experiments are reproduced at several constant flow rates with different $\mathrm{NaCl}$ concentrations between the two fluids and different density differences.

\section{EleCtricAl MEASUREMENT PROTOCOL OPTIMISATION}

A sensitivity analysis (Furman et al., 2007) is necessary to estimate the best series of quadripoles to describe the dispersion front on each time-step, while minimizing the acquisition time. First we did a set of experiments where the pumping was stopped when the tracer filled half of the porous medium. In these conditions gravity stabilizes the front and its position is fixed. We have tested several standard protocol measurements (Wenner-Schlumberger, gradient, dipole-dipole). The first results show that the measurements are strongly perturbed by the resistive edges of the plexiglas tank. In order to remove this effect, data have to be normalised (Daily et al., 1995; Nimmer et al., 2008) and the inversion parameters are optimised to produce reliable models of conductivity distribution. Archie's law and linear relationship between conductivity and concentration (Fig. 2) allows to relate the bulk conductivity of each model to $\mathrm{NaCl}$ concentration. Vertical variations of dye concentrations estimated by video (red curve) and $\mathrm{NaCl}$ estimated by ERT (black curve) are compared. For all experiments, the two concentration curves are shifted: the mean position of the $\mathrm{NaCl}$ mixing front appears to be in advance in comparison to the dye. This shift is probably due to dye trapping in dead end pore zones and adsorption on particle surfaces.

\section{DYNAMIC MONITORING OF THE MIXING FRONT}

Tests carried out for a static front position allow the efficiency of each measurement protocol to be evaluated in description on the fluids interface. We found that a transversal dipole-dipole configuration with 190 quadripoles is best adapted to the geometry of our medium. The temporal resolution is also optimised: each time step is performed in 5 minutes while 30 minutes were needed for the measurements in static conditions. Yet, the continuous tracer propagation causes a temporal shift between the first and the last measurements of each time step. This drawback is corrected assuming a linear conductivity variation with time. Data analyses and inversion parameters are similar as in the case of static fluids (Fig. 3), vertical variations of concentrations estimated by both methods present the same tendencies.

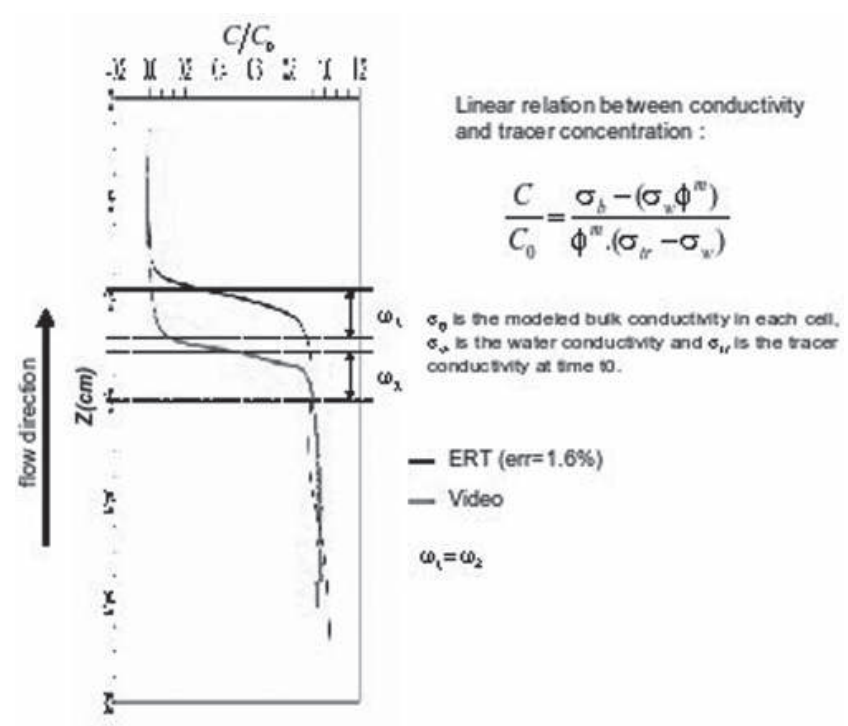

Figure 2: Vertical variations concentrations of $\mathrm{NaCl}\left(\mathrm{C}_{0} \mathrm{C}_{0}\right)$ and dye obtained by ERT (black curve) and video analysis (red curve).

Thickness and mean front position on first time steps are similar (Fig. 3), but the tracer propagation creates a shift of the mean front position which increases upward during the experiment.

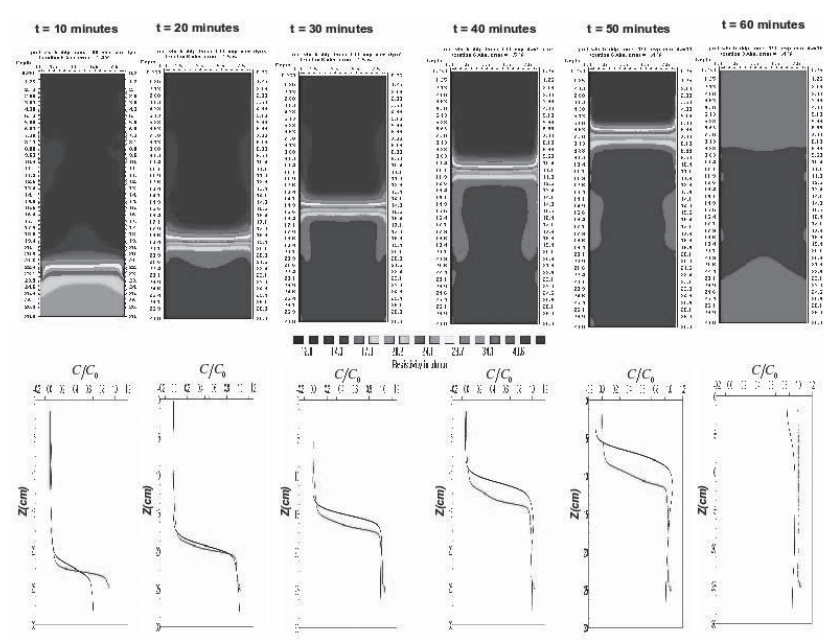

Figure 3 (see color plate): Dynamic tracer follow-up in terms of electrical resistivity distribution and comparison with relative concentrations estimated on each time step. 


\section{Conclusions}

- Optimisation of the electrical measurements protocol provides an acceptable compromise between spatial and temporal resolutions.

- Dynamics monitoring gives a reliable estimation of position and thickness of the mixing front.

- The shift observed between video and ERT is caused by adsorption and dye trapping, which may be quantified by our method.

In the future, it will be necessary to check on the repetitiveness of the results with several density differences and flow rates. The system will also be complexed, while adding permeability heterogeneities and a $2 \mathrm{D}$ vertical fracture.

\section{References}

Archie, G. E., 1942. The Electrical Resistivity Log as an Aid in Determining Some Reservoir Characteristics. J. Petroleum Technol. Tech. Pub., 5 p.
Binley, A., Henry-Poulter, S. and Shaw, B., 1996. Examination of solute transport in an undisturbed soil column using electrical resistance tomography. Water Resources Research, 32: 763-769.

Flowers, T. C. and HunT, J. R., 2007. Viscous and gravitational contributions to mixing during vertical brine transport in water-saturated porous media. Water Resources Research, 43, W01407.

Furman, A., Ferré, T. P. A. and Health, G. L., 2007. Spatial focusing of electrical resistivity surveys considering geologic and hydrologic layering. Geophysics, 72: 65-73.

Kemna, A., Vanderborght, J., Kulessa, B. and Vereecken, H., 2002. Imaging and characterisation of subsurface solute transport using electrical resistivity (ERT) tomography and equivalent transport models. Journal of Hydrology, 267: 125-165.

Oldenborger, G. A., Knoll, M. D., Routh, P. S. and LABRECQUE, D. J., 2007. Time-lapse ERT monitoring of an injection/withdrawal experiment in a shallow unconfined aquifer. Geophysics, 72: 177-187.

Slater, L., Binley, A. M., Daily, W. and Johnson, R., 2000. Cross-hole electrical imaging of a controlled saline tracer injection. Journal of Applied Geophysics, 44: 85-102. 